\title{
The Effects of Stacking Sequence Layers of Hybrid Composite Materials in Energy Absorption under the High Velocity Ballistic Impact Conditions - An Experimental Investigation
}

Elias Randjbaran, Rizal Zahari, Dayang Laila Majid, Nawal Aswan Abdul Jalil, Ramin Vaghei, Ramin Ahmadi

Faculty of Engineering, Universiti Putra Malaysia, Malaysia

\section{Article Info \\ Article history: \\ Received Jun 16, 2014 \\ Revised Aug 15, 2014 \\ Accepted Aug 26, 2014}

\section{Keyword:}

Ballistic impact

Carbon fibre

Energy absorption

Glass fibre

Hybrid composite

Kevlar fibre

Stacking Sequence

\begin{abstract}
In the current study, the effects of stacking sequence layers of hybrid composite materials on ballistic energy absorption, which were fabricated from Kevlar, carbon, glass fibres and resin have been experimentally investigated at the high velocity ballistic impact conditions. All the samples have equal mass, shape and density, but they have different stacking sequence layers. After running the ballistic test in the same conditions, the final velocities of the bullets showed that how much energy absorbed by the samples. The energy absorption of each sample through the ballistic impact has been calculated, accordingly, the decent ballistic impact resistance materials could be found by conducting the test. This paper can be further studied in order to characterise the material properties.
\end{abstract}

Copyright $@ 2014$ Institute of Advanced Engineering and Science. All rights reserved.

\section{Corresponding Author:}

Elias Randjbaran,

Faculty of Engineering,

Universiti Putra Malaysia,

43400 UPM Serdang, Selangor Darul Ehsan, Malaysia.

Email: elias@gmx.co.uk

\section{INTRODUCTION}

Progressions in the use of hybrid composite materials for the structure of aircraft and automobile industries have risen considerably over the last decade. This has been driven by the need for improved performance requirements in terms of stealth, payload, range, stability and at the same time, a reduction in costs in terms of maintenance, operation and construction. Much experience in the use of hybrid composites in the aerospace industries has been achieved from the design of composite airplanes, which were designed using high stiffness requirements and not for all the parts of the current body of airplanes being planned. The stiffness of composites can be determined equitably accurately using the particular tests and material properties from standard material characterisation tests. However, with more demanding requirements this has changed and the minimisation of damage is something that is now required in order to satisfy higherperformance demands. This is not as simple as optimising the elastic stiffness of the structure due to the complex damage modes that can occur in hybrid composites. This is particularly true under high velocity ballistic impact scenarios.

Carbon, glass, and Kevlar fiber hybrid composites are susceptible to accidental from low to highenergy impacts of such hazards as dropped tools during maintenance, runway debris, hail-stones and sandstorm. These impacts can bring about considerable strength reduction, and the localized damage is potentially a source of mechanical weakness, particularly under the mechanical applications [1]-[3]. 
Furthermore, the damage consequent upon a minor impact can grow to large size under the mechanical applications. The nature of the impact damage in hybrid composite laminates ranges from surface damage and subsurface damage to complete penetration, depending upon the impact loading conditions. Generally, under the ballistic impact, damage obtains only in constant plies of a laminate, resulting in socalled part through-the thickness damage. This sort of damage is of a complicated form, consisting of fluctuating amounts of matrix cracks, fiber cracks, and de-lamination. The complexity of the damage makes it difficult to assess the precise mechanisms controlling strength reduction. Among these modes of impact damage, de-lamination has the most detrimental effects on laminate stiffness and strength, and has received a considerable amount of attention [4]-[7].

High velocity impact involves projectiles moving at higher velocities such that the local target materials behave like fluids, and the stress induced by the impact is many times the material strength.

The goal for this classification is the energy transfer in the middle projectile and target; energy waste and damage propagation mechanisms withstand extreme transfigured as the velocity of the projectile changes. One of the possible ways of magnifying the ballistic limit is to employ textile composites. The kinetic energy of the projectile once impacted into the target is scattered and absorbed in various lanes by the target. The main energy-absorbing mechanisms throughout the ballistic impact are: kinetic energy absorbed by the moving bullet on the back face of the target, energy absorbed due to tensile failure of the primary fibres' layer then energy absorbed due to the elastic de-formation of the secondary fibres' layer, energy absorbed due to matrix cracking and de-lamination and frictional energy absorbed in the course of penetration. At high velocity or ballistic impact, the response of the structural element is governed by the „local ${ }^{\text {ee }}$ behaviour of the material in the region of the impacted zone; the impact response of the element is generally independent of its assist conditions. The contact cycle of the impactor is smaller than the time cycle of the lowest vibrational mode of the structure. Hyper impact involves projectiles moving at extremely high velocities such as the local target materials behave like fluids, and the stress induced by the impact is many times the material strength [8].

Tariq et al., mentioned that as the plate specimen thickness continued to increase, the damage on the lower skin decreased so little which could not be seen. Moreover, as the plate thickness increased, the maximum impact load and impact energy increased relatively. Impact damage was in the form of perforation, fibre breakage and matrix cracking [9].

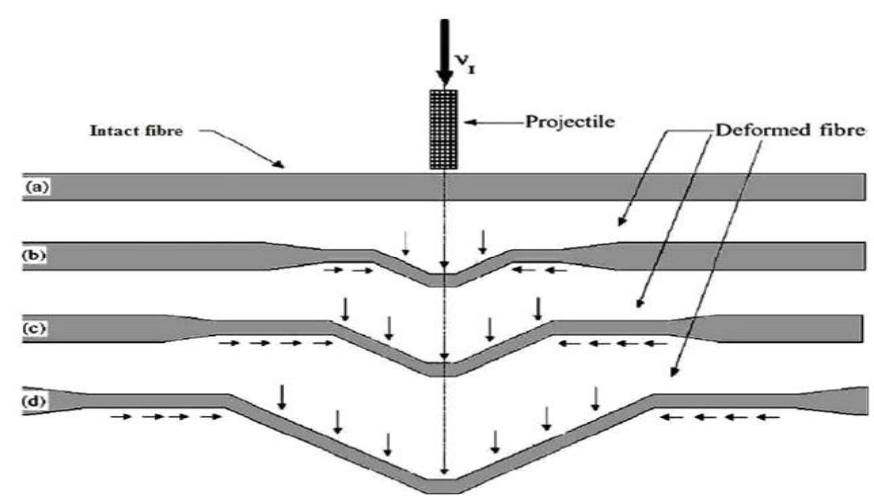

Figure 1. Configuration of a fibre before and after transverse impact: (a) before impact; (b)-(d) after impact

\section{MANUFACTURING PROCEDURE}

2.1. Materials

Traditionally, aerospace composites have been composed of high-stiffness carbon fibers to maintain dimensional stability under high-performance application. The stiffness property is often associated with a particular susceptibility to impact damage and a corresponding reduction of mechanical properties. However, such structures are expected to only encounter few unintentional impacts. Composite structures for military ground vehicles, on the other hand, are designed to absorb multiple high-energy impacts but have much less dimensional restrictions. Since softer materials tend to dissipate more energy during impact, a low modulus/high strength alternative would be well suited for backing panel composites.

Figure 2 shows the three types of fibres, including glass, carbon, and Kevlar, which were used in fabricating the specimens.

The Effects of Stacking Sequence Layers Of Hybrid Composite Materials in Energy... (Elias Randjbaran) 


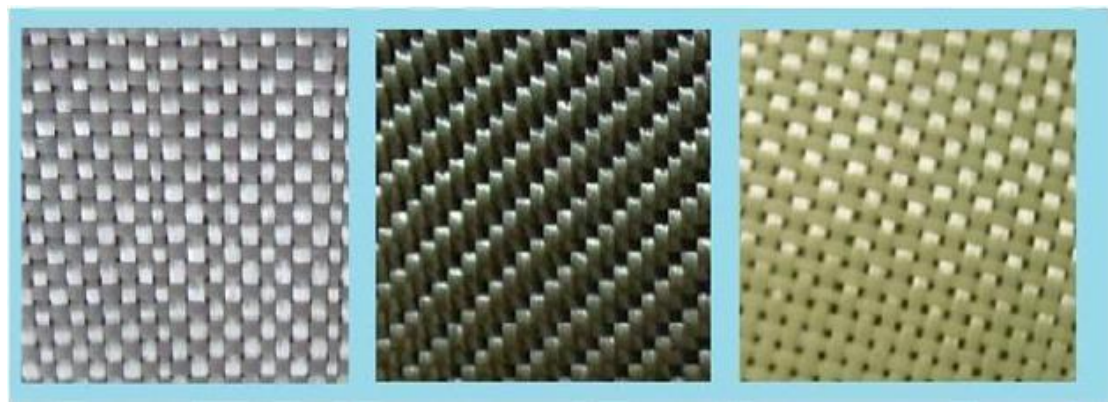

Figure 2. Left to right; Glass, carbon, and Kevlar fibre

Table 1 illustrates the mechanical properties, such as strength, failure strain, and Young's Modulus of carbon, glass, and Kevlar fibres.

Table 1. Mechanical properties of fibres have been used in

\begin{tabular}{cccc}
\hline Fibre & Strength $(\sigma)(\mathrm{GPa})$ & $\begin{array}{c}\text { Failure } \\
\text { Strain( }(\varepsilon) \\
(\%)\end{array}$ & Modulus(E)(GPa) \\
\hline Carbon fibre & 3.8 & 1.76 & 227 \\
E-Glass & 3.5 & 4.7 & 74 \\
Kevlar@ KM-2, & 3.4 & 3.55 & 82.6 \\
600 denier & & & \\
\hline
\end{tabular}

Kevlar KM2 fabrics are widely used to produce personnel protection systems because of their impact-resistant properties. To understand the deformation process of a fabric armour system during impact, many aspects of fabric, such as its material properties, fabric structure, projectile geometry, impact velocity, multiple ply interaction, far-field boundary conditions, and friction, must be studied [11]. The Kevlar fabric used in all composite target constructions was plain-woven Hexcel Aramid (polyparaphenylene terephthalamide), high-performance fabric Style 706 (Kevlar KM-2, 600 denier) with a real density of 180 $\mathrm{g} / \mathrm{m} 2$.

Table 2 illustrates the mechanical properties including flexural strength, hardness, adhesive strength, compressive modulus, tensile strength, and impact strength of the liquid epoxy resin and hardener.

Table 2. Mechanical Properties of the Liquid Epoxy Resin are EPOKUKDO YD-128, and hardener is Polyamide - Domide (A.V: 350)

\begin{tabular}{cccccc}
\hline $\begin{array}{c}\text { Flexural Strength } \\
(\mathrm{MPa})\end{array}$ & $\begin{array}{c}\text { Hardness } \\
\text { (Rockwell) M } \\
\text { Scale }\end{array}$ & $\begin{array}{c}\text { Adhesive strength } \\
\text { (Iapshear) } \\
(\mathrm{Kg} / \mathrm{cm} 2)\end{array}$ & $\begin{array}{c}\text { Compressive } \\
\text { Modulus } \\
(\mathrm{MPa})\end{array}$ & $\begin{array}{c}\text { Tensile Strength } \\
(\mathrm{MPa})\end{array}$ & $\begin{array}{c}\text { Impact Strength } \\
\left(\mathrm{Kg} . \mathrm{cm}^{2} / \mathrm{cm}^{2}\right)\end{array}$ \\
\hline 780 & 80 & 65 & 636 & 400 & 2.1 \\
\hline
\end{tabular}

Room temperature curing and the ratios of 50 parts epoxy resin (EPOKUKDO YD-128) to 50 hardener (Polyamide - Domide (A.V: 350)) by weight being cured after seven days at $20^{\circ} \mathrm{C}$.

\subsection{Preparation of the Specimens}

Hand lay-up is the simplest and oldest open moulding method of the composite fabrication processes. Glass or other reinforcing mat or woven fabric or roving is positioned manually in the open mould, and resin is poured, brushed, or sprayed over and into the glass plies. Entrapped-air is removed manually with squeegees or rollers to complete the laminate structure. Room temperature curing epoxies are the most commonly used matrix resins. A catalyst initiates curing in the resin system, which hardens the fibre-reinforced resin composite without external heat, and kept them in-room temperature $\left(19{ }^{\circ} \mathrm{C}\right.$, Humidity $13 \%$ ). Table 3 illustrates the ordering and sequence of fibres plies in each hybrid composite materials. 
Table 3. The fabricated composite sheets are divided into five groups

\begin{tabular}{ccccc}
\hline HYBRID 1 & HYBRID 2 & HYBRID 3 & HYBRID 4 & HYBRID 5 \\
\hline Kevlar & Glass & Kevlar & Glass & Kevlar \\
Carbon & Carbon & Glass & Kevlar & Carbon \\
Glass & Kevlar & Carbon & Carbon & Glass \\
Kevlar & Carbon & Glass & Carbon & Glass \\
Glass & Kevlar & Carbon & Glass & Carbon \\
Carbon & Glass & Kevlar & Kevlar & Kevlar \\
\hline
\end{tabular}

\subsection{Experimental Testing Procedure}

The experimental setup was according to guidelines given in the NIJ Standard 0108.01, shown in Figure 3. The standard testing methods for measuring the impact response and resulting from residual properties applied in the research were initially developed by the aerospace industry to calculate the effects of bird strikes or accidental tool drops on a composite aircraft structure. These tests have been approved for years as the primary standard for damage tolerance testing of composite material systems. With the development of modern composite systems for all vehicle structures, nevertheless, the conditions used in these tests are not remarkably suitable to those expected of these new material systems. Backing panels on military ground vehicles are designed to absorb large loads from high-energy impacts. In order for these systems to survive versus multiple impacts, they must be able to scatter the incoming energy and have superior mechanical tolerance to the damage likely to be induced. Consequently, it is essential to employ materials, which describe excellent energy absorption and strength. Given that, these structures are presently under development, there is no single system or design guideline that has been established.

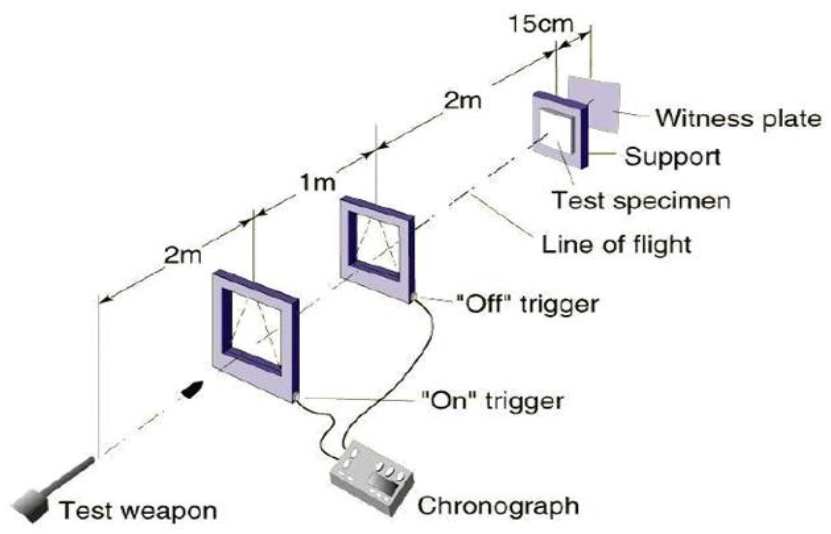

Figure 3. Schematic of ballistic test setup following the NIJ Standard (NIJ-0108.01, 1985)

Compressed Helium gas used as the working fluid. Helium gas was used because it has high thermal conductivity, colourless, odorless, tasteless, commercially available, lighter than air, non-toxic, the velocity of sound was about three times the velocity of sound in air, reduces the distorting effects of temperature variations, and less dense than atmospheric air which actually create low drag to the bullet. The air pressure from the compressor was kept constant at $0.6 * 103 \mathrm{kPa}$ while Helium pressure was increased from $1.4 * 103$ $\mathrm{kPa}$ to $4.1 * 103 \mathrm{kPa}$. However, the gun tunnel can be operated at maximum of $21 * 103 \mathrm{kPa}$. The air pressure was used to open the Helium gas valve at the gun tunnel barrel after the gun tunnel barrel trigger was pushed. The gun tunnel barrel length is about 4-metre measured from the bullet reload section and a test section chamber was placed at the end of the gun tunnel barrel. Test section is made of high strength steel that give out most protection during the experiment. The test section chamber is $600 \mathrm{x} 450 \mathrm{x} 450 \mathrm{~mm}$, length, height, and width respectively as shown in Figures 5-8. It gives enough space for the bullet to be calibrated and stopped. The trigger for the gun tunnel is the place near to the bullet reload section where far away from the test section chamber making much safety working area. 


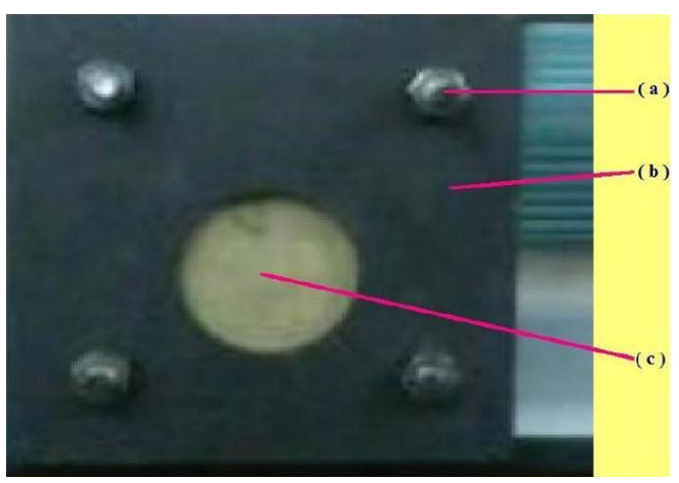

Figure 4. (a) Hexagon Bolts, (b) Steel frame for mounting, and (c) Specimen

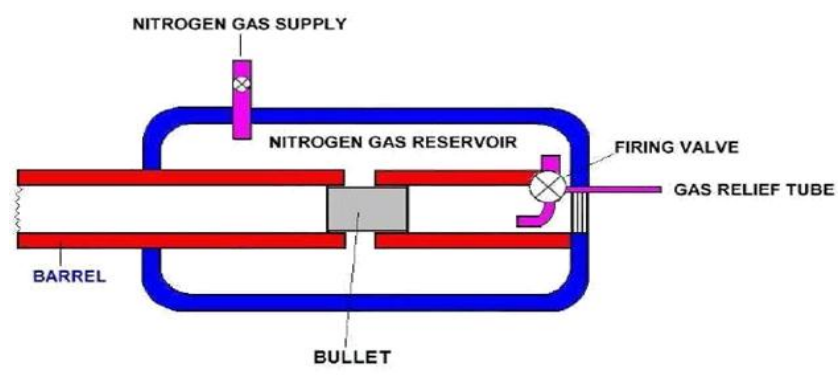

Figure 5. Schematic of gas gun and bullet in the barrel

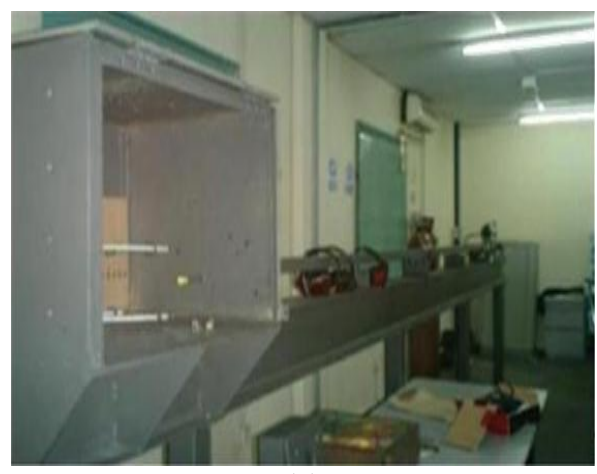

(a)

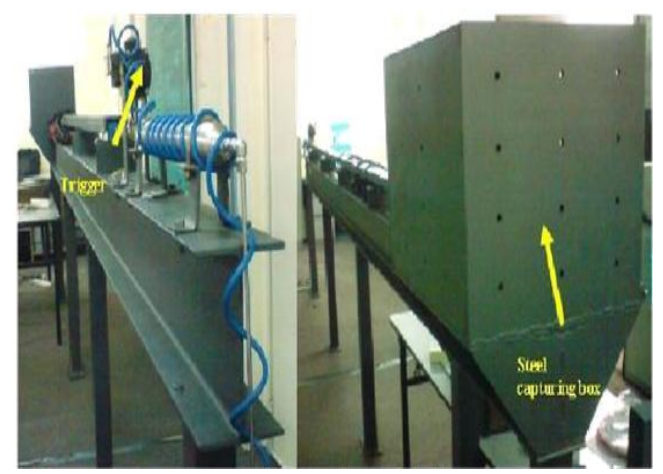

(b)

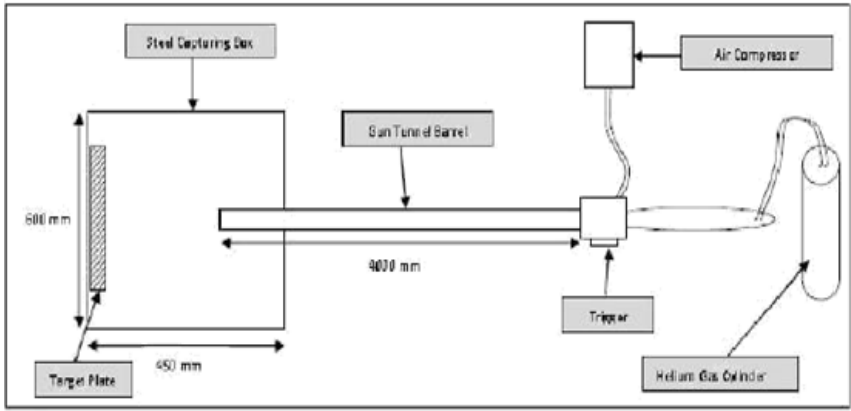

(c)

Figure 6. (a) Gun equipment [9], (b) Gas gun, and (c) Experimental set-up impact [10] 


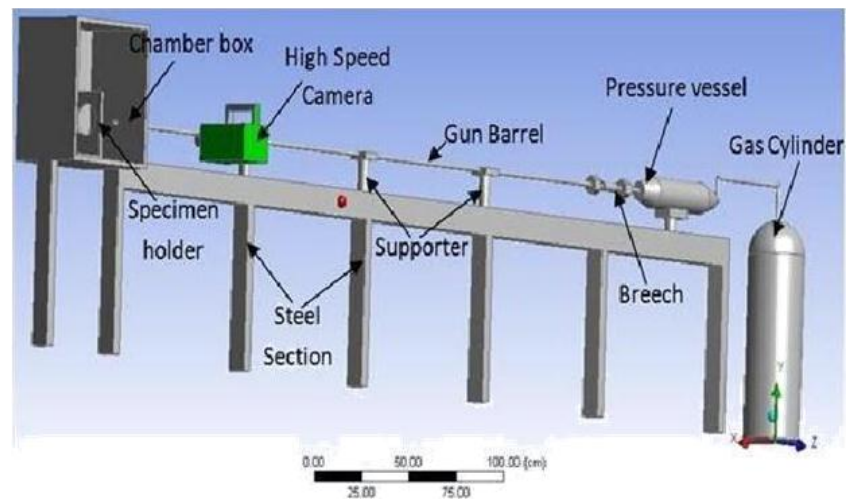

Figure 7. Schematic of Gas gun tunnel instrument for impact test [12]

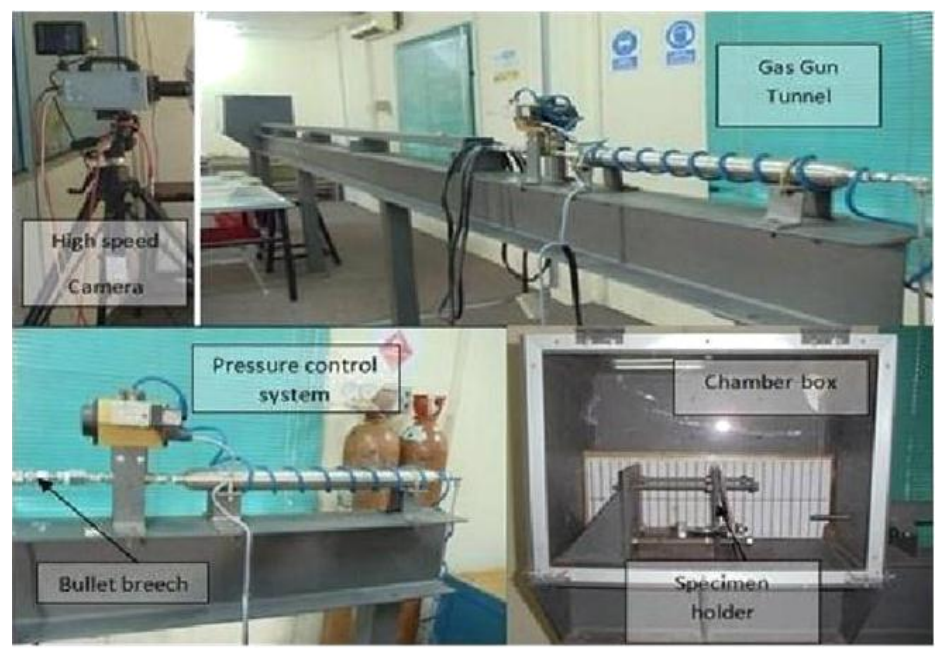

Figure 8. Gas gun tunnel for conducting the ballistic impact test [12]

The high speed camera used state of the art CMOS sensors available in monochrome or colour with 2GB of memory. It is able to capture colour images up to 200,000 fps at 512 X 12 bit resolutions. Recorded images can be played back and viewed immediately after image capture on PC. The video playback unit allocates for "step" fashion image review, allows the user to set the start and end points for image review, allows the user to "jump" to the trigger point, the START point or the END point or the END point of the image area. Image playback can be in a single segment or in a loop. Figure 6 shows the actual gun tunnel used for the experiment.

Figure 9 shows the schematic of the mild steel bullet being used in the experiment. Cylindrical bullets were used in the experiment to calibrate the bullet speed by varying Helium gas pressure. Bullet used in the experiment was made of mild steel with 5.75 grams of weight. The length is 13.07 millimetres by 8.48 millimetres in diameter. It has a smooth cylindrical surface to have minimum friction and drag during its flight. Together with that, oil also being used as a tube to the bullet which helps to reduce surface friction contact.

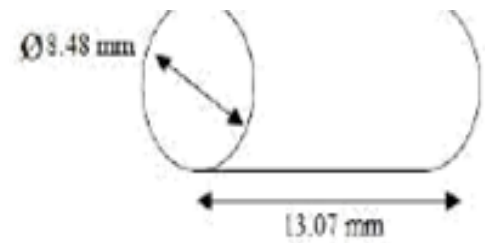

Figure 9. Schematic of the mild steel bullet 


\subsubsection{Calculation of Velocity}

High frame rates are required a sensor with good sensitivity, either a very good shuttering system or a very fast strobe light, and also requires some means of capturing successive frames, either with a mechanical device or by moving data off electronic sensors very quickly. In the such higher frame rates, it is found that a slight difference in debris cloud formation was capture $\mathrm{d}$ in the inter-frame of 4 microseconds which is equivalent to the 250,000 frames per second, and the debris fragment distributions appear to be slightly narrower and thinner at cryogenic temperature (Figure 10) [13].

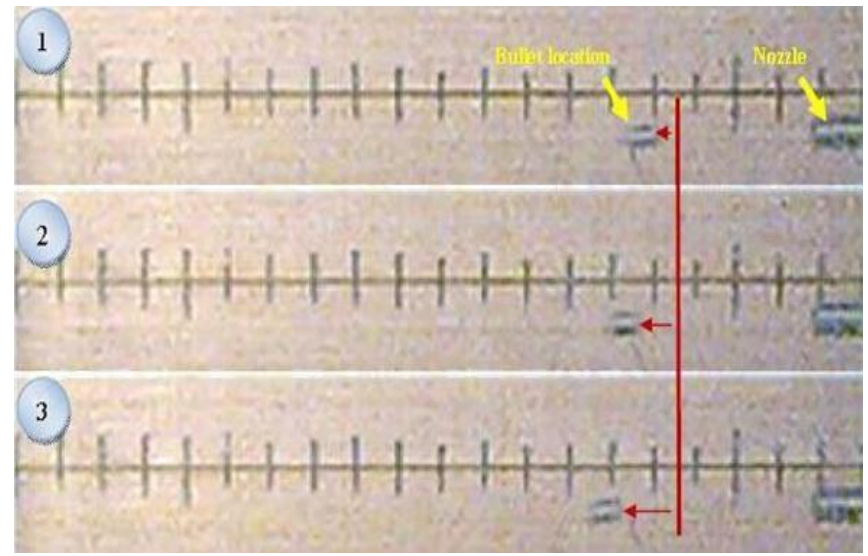

Figure 10. Three frames of snapshots taken via the high speed camera (300 psi He, at 30,000 frames per seconds)

\subsubsection{Calculation of Energy}

It is an established fact that absorbed energy by a specimen in ballistic test is a means to quantify impact-penetration resistance. So, the absorbed Kinetic energy of armour-projectile interaction can be linked by Equation (1) where are defined as the total Kinetic energy has been absorbed by the specimen, the Kinetic energy of the projectile prior to impact, and the residual kinetic energy after penetrating through the specimen, respectively.

From this point, the equation (1) can be further derived into the Equation (2) and (3), which are using the classical Physics ${ }^{\text {ee }}$ relationship describing the Kinetic energy of a moving object whereas $\mathrm{mp}$ is the mass of the projectile Viniatial and Vfinal are the projectile initial and final velocities:

$$
\begin{aligned}
& \mathrm{E} \text { abs }=\mathrm{E} \text { initial }-\mathrm{E} \text { final } \\
& \mathrm{E} \text { abs }=0.5 \mathrm{mp} \text { Vinitial } 2-0.5 \mathrm{mp} \text { Vfinal } 2 \\
& \mathrm{E} \text { abs }=0.5 \mathrm{mp}(\text { Vinitial } 2-\text { Vfinal } 2)
\end{aligned}
$$

\section{RESULTS AND DISCUSSION}

Figure 11 shows the process of penetration of bullets into the specimens. The amount of ejected materials in all the 6 different types of specimens, including the five hybrids and the pure carbon fibre, which are diverse to each other.

The amount of ejected materials is a significant evidence for absorbing energy. If the amount of ejected materials increase, the energy absorption will consequently decrease. Therefore, among the hybrid composite materials, the highest amount of ejected materials belongs to hybrid 1 with $19.84 \%$, and the lowest belongs to hybrid 2 with $3.54 \%$.

Table 5 illustrates a set of experimental data in relation to the sorts of changes, which are the manifestation of the amount of absorbed ballistic energy (in a Joul scale unit) of each of the specimens according to final velocities of each bullet (in metre per second) at $182 \mathrm{~m} / \mathrm{s}$ as an initial velocity. In general, there are some variation trends unveiled throughout the figure of the information. 


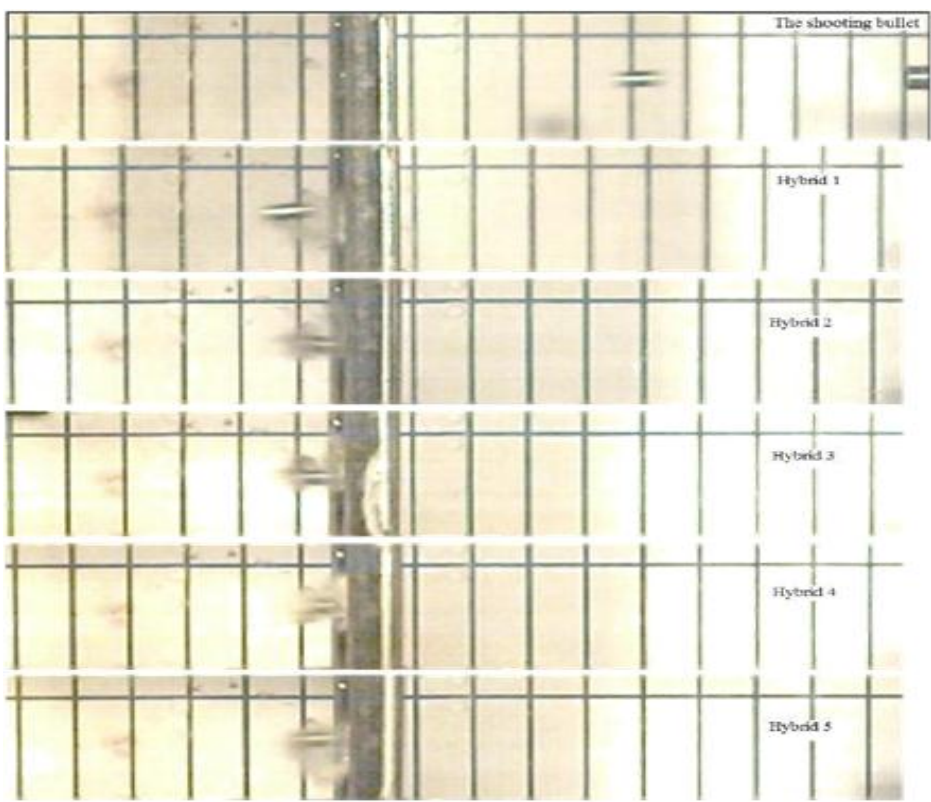

Figure 11. Process of penetrating the bullets into the specimens

Table 5. Final velocity and energy absorption of the 6 types of specimens at $182 \mathrm{~m} / \mathrm{s}$ as the initial velocity

\begin{tabular}{ccc}
\hline Specimen & $\begin{array}{c}\text { Final Velocity } \\
(\mathrm{Vf}),(\mathrm{m} / \mathrm{s})\end{array}$ & $\begin{array}{c}\text { Ballistic Energy } \\
\text { Absorption, (J) }\end{array}$ \\
\hline Hybrid 1 & 14.36 & 94.36 \\
Hybrid 2 & 4.47 & 95.17 \\
Hybrid 3 & 8.76 & 95.01 \\
Hybrid 4 & 5.28 & 95.15 \\
Hybrid 5 & 8.21 & 95.04 \\
Carbon & 26.87 & 93.16 \\
\hline
\end{tabular}

Turning to the details, it can be demonstrated that in Hybrid 2, the minimum final velocity is 4.47 $\mathrm{m} / \mathrm{s}$, and maximum final velocity, among the Hybrid specimens, is in Hybrid 1 (14.36 m/s). And also in Hybrid 2, the maximum energy could be absorbed (95.17 J), among the Hybrid specimens, the minimum of absorbed energy in Hybrid 1 (94.36 J).

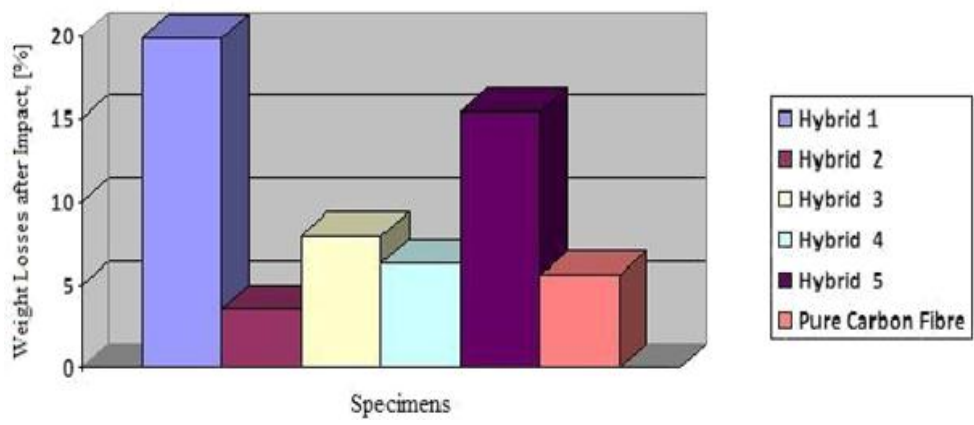

Figure 12. Comparison of the specimens weight losses' percentages after ballistic impact

Figure 13 shows the final velocities of the bullets in 6 types of specimens, while the initial velocity is $182 \mathrm{~m} / \mathrm{s}$. Hybrid 2 demonstrated the reduction of the velocities of the bullets less than the other specimens. Among the Hybrid specimens, the final velocities of Hybrid 2, Hybrid 3, Hybrid 4, and Hybrid 5 are although close to each other but they are not united, and the difference among them is $4.29 \mathrm{~m} / \mathrm{s}$.

The Effects of Stacking Sequence Layers Of Hybrid Composite Materials in Energy... (Elias Randjbaran) 
Furthermore, Hybrid 2 and Hybrid 4 are approximately at the level and the difference between them is 0.81 $\mathrm{m} / \mathrm{s}$. Likewise, Hybrid 3 is comparatively at the level with Hybrid 5 and the difference between them is 0.55 $\mathrm{m} / \mathrm{s}$. Additionally the difference between the maximum and minimum final velocities is $12.51 \mathrm{~m} / \mathrm{s}$.

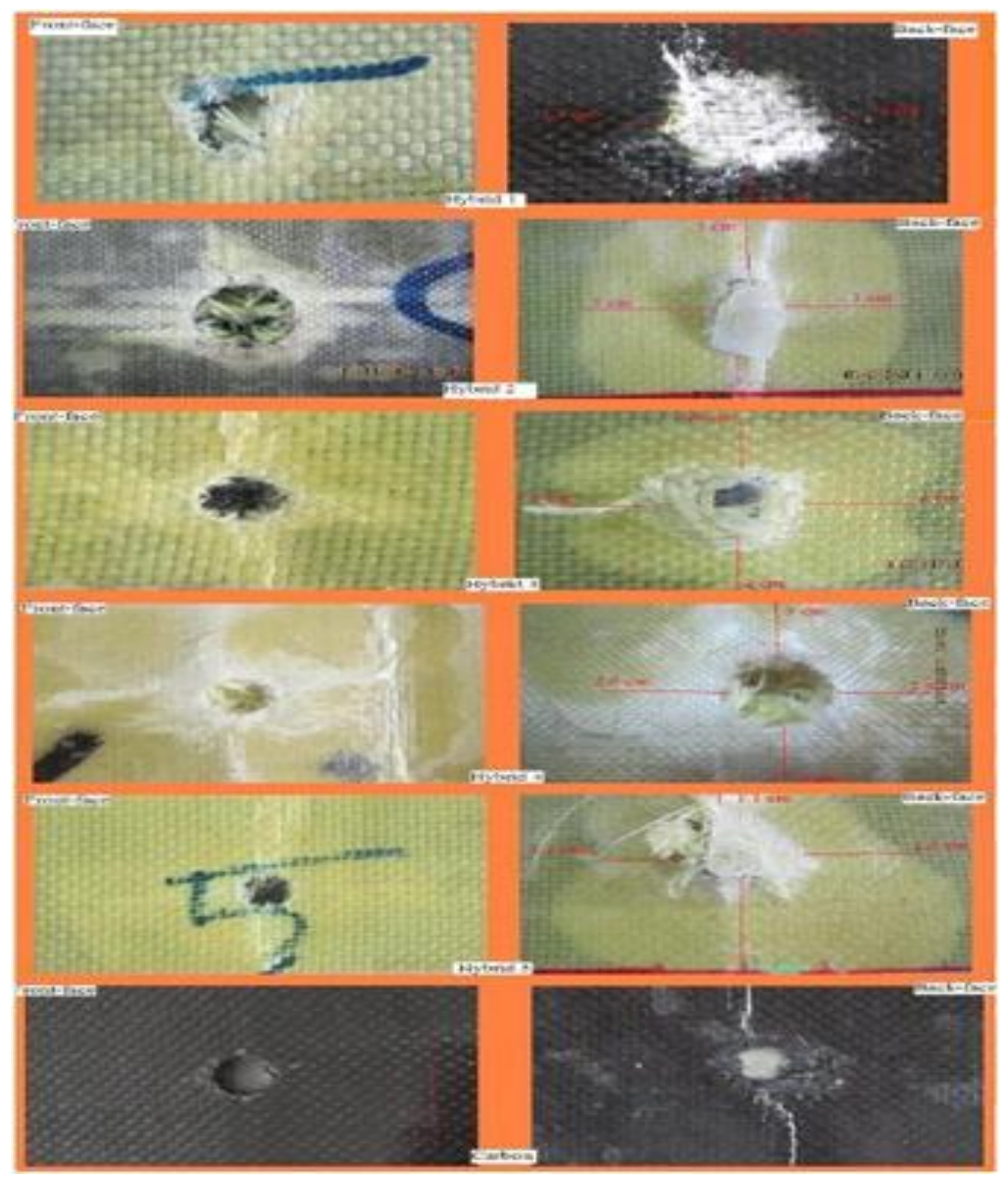

Figure 13. Damage profiles: (left) impact-induced damage profile viewed from the front face (impacted) and (right) Impact-induced damage profile viewed from the back face

Figure 14 and 15 show the changes in ballistic impact energy absorption of Hybrid 1 to Hybrid 5 and the pure Carbon fibre.

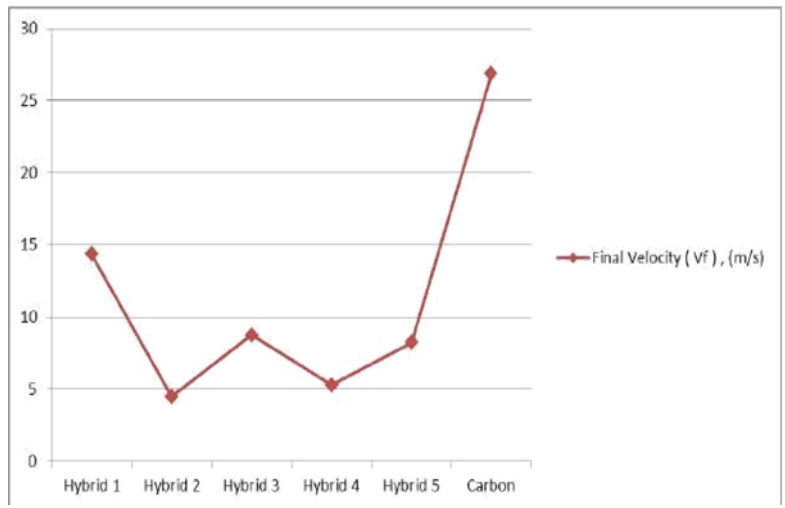

Figure 14. Final velocities of the bullets in 6 types of specimens 


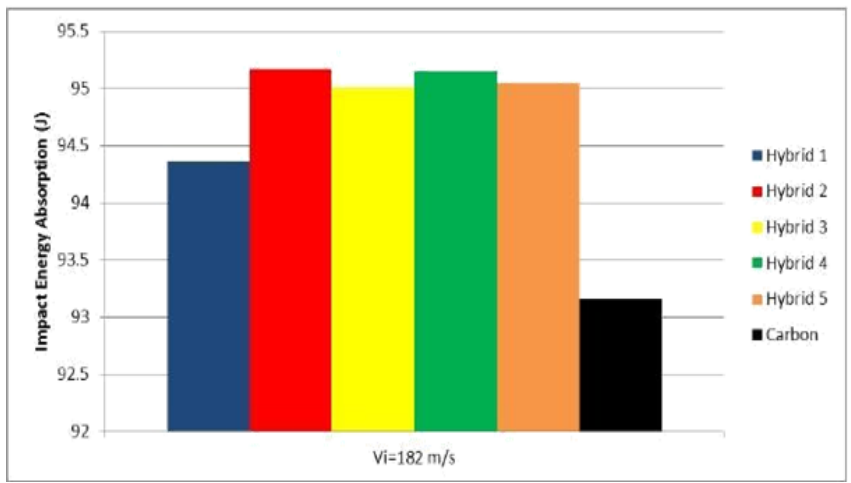

Figure 15. Comparing the the amount of energy absorption in 6 specimens of $182 \mathrm{~m} / \mathrm{s}$ as the initial velocity

The highest concentration of energy absorption is ranging around 95 joules, from a maximum of 95.17 J for a minimum of 95.01 J, such as Hybrid 2 (95.17 J), Hybrid 4 (95.15 J), Hybrid 5 (95.04 J), and Hybrid 3 (95.01 J). The amount of energy absorption of Hybrid 2 and Hybrid 4 are close to each other, also the difference between both of them is $0.02 \mathrm{~J}$. Another pair of Hybrids, which have approximately similar energy absorption, are Hybrid 3 and Hybrid 5, the narrow difference between them is $0.03 \mathrm{~J}$.

Hybrid 2 has the maximum ballistic impact energy absorption, in contrast, Hybrid 1 ( $94.36 \mathrm{~J}$ ) possesses the minimum ballistic impact energy absorption. And then the disparity between the maximum and minimum ballistic impact energy absorption is $0.81 \mathrm{~J}$.

Figure 16 shows the relationship between that the amounts of ballistic impact energy absorption and the final velocities of the bullets, when the initial velocity of the bullets is 182 metre per hour.

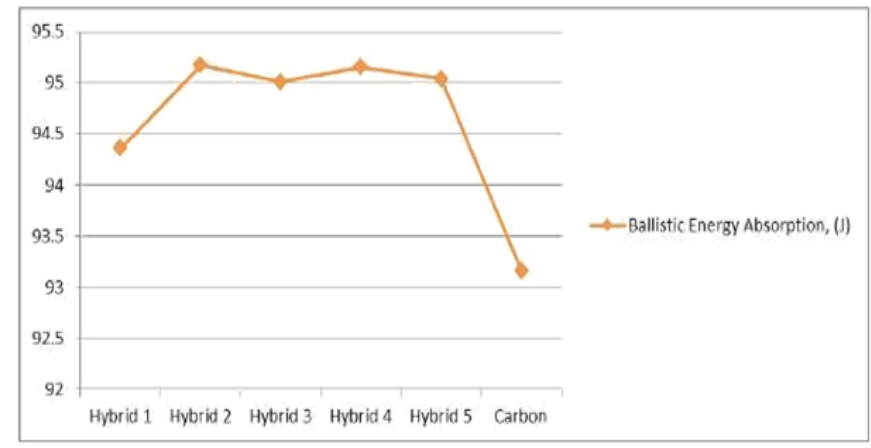

Figure 16. The varieties of final velocities of the bullets in 6 specimens

$\mathrm{X}$-axis indicates the final velocity in metre per hour and $\mathrm{Y}$-axis indicates the amounts of ballistic impact energy absorption in joules. Six different types of specimens, including Hybrid 1 to Hybrid 5 and the pure carbon fibre, have been investigated by conducting the impact test. The most desirable specimen should follow these characteristics: first, reduce the final velocities of the bullets to its lowest level. Second, should absorb the highest rate of ballistic impact energy.

Hybrid 2 and Hybrid 4 demonstrated close behaviour in terms of the final velocity and the energy absorption which the final velocity difference of them is $0.81 \mathrm{~m} / \mathrm{s}$ and the energy absorption difference is 0.02 J. Besides, Hybrid 3 and Hybrid 5 are showing the same close behaviour which velocity difference of them is $0.55 \mathrm{~m} / \mathrm{s}$ and the difference of energy absorption is $0.03 \mathrm{~J}$.

It can be concluded that the amounts of ballistic impact energy absorption have increased, whereas the final velocities of the bullets have gone down slightly. Among the Hybrids, the strongest is Hybrid 2 and the weakest is Hybrid 1. Furthermore, among all of them, the strongest one is Hybrid 2 and the weakest is the pure carbon fibre.

Figure 17 demonstrates the rate of energy absorption, shown as a percentage, in the six different types of specimens, including Hybrid 1 to Hybrid 5 and the pure carbon fibre. The $\mathrm{X}$-axis indicates the types of the specimens and $\mathrm{Y}$-axis indicates the percentage of ballistic energy absorbed. 


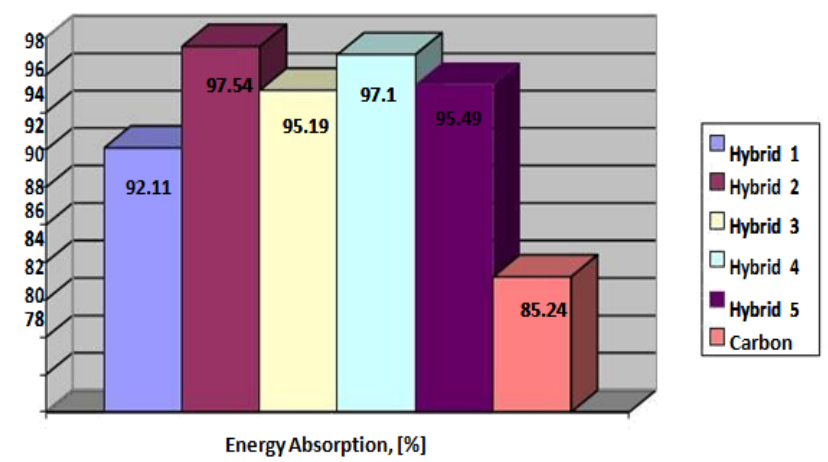

Figure 17. Percentage change in energy absorption (or energy dissipated) due to the perforation of the specimens at the different final velocities

Hybrid 2 has maximum energy absorption and Hybrid 1 (among the Hybrids) has a minimum energy absorption. Afterward, the difference between them is $5.43 \%$. An average percentage of the ballistic impact energy is about $95.49 \%$. Hybrid 2, Hybrid 4, and Hybrid 5 are above the average line, as a consequence, Hybrid 1 and Hybrid 3 are below the average line.

Table 6 illustrates the ranking of energy absorption from the maximum to the minimum level.

Table 6. Ranking the specimens according to the ballistic energy absorption

\begin{tabular}{cc}
\hline Rank & Specimen \\
\hline 1 & Hybrid 2 \\
2 & Hybrid 4 \\
3 & Hybrid 3 \\
4 & Hybrid 5 \\
5 & Hybrid 1 \\
6 & Carbon \\
\hline
\end{tabular}

\section{CONCLUSION}

The results show, first, the Hybrid 2 has the superlative energy absorption. Second, it can be concluded that stacking the first layer with glass fibre is better than to use the Kevlar fibre. Third, using the combination of carbon and glass is more efficient than using in the central layers. Fourth, using the carbon fibre is not recommended at the last layer.

\section{REFERENCES}

[1] T. Ishikawa, et al., "Compos.” Sci. TechnoL, 1995, Vol. 65, pp. 349.

[2] D. Stavropoulos, et al., J. Mater. Sci, 1997, Vol. 32, pp. 931.

[3] C. J. Jih, et al., “J. Compos,” Mater, 1993, Vol. 27, pp.684.

[4] M. J. Pavier, et al., "Compos," Sci. Technol., 1995, Vol. 65, pp. 157.

[5] B. Jang, et al., "Compos,” Science Technology, 1989, Vol. 34, pp. 305.

[6] S. Y. Gweon, et al., J. Material Science, 1992, Vol. 27, pp. 2035.

[7] E. Wu, et al., J. Composite Material, 1993, Vol. 27, pp. 1443.

[8] N. K. Naik, et al., "Composite structures under ballistic impact," Composite Structures, 2004, Vol. 66, pp. 579-590.

[9] Mohamed Thariq Hameed Sultan, et al., "High Velocity Impact Damage Analysis for Glass Epoxy-Laminated Plates," Advanced Materials Research (Volumes 399 - 401), New Materials, Applications and Processes, 2011, pp. 2318-2328.

[10] Cheeseman B. A., et al., "Ballistic Impact Into Fabric and Compliant Composite Laminates," Composite Structure, 2003, Vol. 61, pp. 161-173.

[11] Ramadhan, et al., "Experimental and Numerical Simulation of Energy Absorption on Composite Kevlar29/Polyester Under High Velocity Impact," Journal of Advanced Science and Engineering Research, 2012, pp. 52-67.

[12] M. F. Abdul Hamid, et al., "PRELIMINARY VELOCITY MEASUREMENT FROM A GUN TUNNEL USING A HIGH SPEED CAMERA," FEIIC Symposium on Engineering and Technology, Kuching, Sarawak, Malaysia: FEIIC, 2008, pp. 6. 